\title{
Visual stimulus complexity and food vs. food alone as rewards for rats'
}

\author{
R. B. MAY, K. L. BEAUCHAMP AND S. POLLOCK ${ }^{2}$ \\ CLAREMONT GRADUATE SCHOOL
}

\begin{abstract}
In three experiments, normally reared hooded rats were exposed to a $\mathrm{T}$ maze with the same black-white pattern in each arm and were later tested with the pattern in one arm changed. Half the Ss received food for entering the unchanged arm and half for entering the changed arm. In all three experiments there was a significant difference between the groups in terms of number of food rewarded responses.
\end{abstract}

\section{Problem}

Sackett, Lee, \& Treat (1963) state that rats raised under sensory deprivation and tested as adults go to food in a $\mathrm{T}$ maze if the food is located in a checkerboard goal. They do not go to food if the food is located in a visually less complex goal; normally raised rats go to food regardless of the visual complexity of the goal. Since there is ample evidence that the choice behavior of normally reared rats can be mediated by stimulus complexity (Berlyne, 1960; Dember \& Earl, 1957), the findings of Sackett et al, may be a special case. For one thing, massed trials were given and perceptual rewards tend to satiate relatively quickly under some conditions of massed practice (Myers \& Miller, 1954). The present experiments involved the following major differences in procedure from the Sackett et al study: (1) only normally reared Ss were used, (2) spaced trials were given, and (3) in the first two experiments the food rewarded alternative was always on the same side of the maze.

\section{Subjeets}

Fifty experimentally naive hooded rats served as Ss. Those in Experiments I and II were 125-145 days, and in Experiment III, 78-82 days old at the beginning of testing. Ss in Experiment I were tamed and adapted to a $23 \mathrm{hr}$. food deprivation regimen for 30 days, and Ss in Experiments II and III were tamed and deprived (23 $\mathrm{hr}$. per day) for 14 days prior to testing.

\section{Apparatus}

The apparatus consisted of a $\mathrm{T}$ maze with arms and stem 4-in square and 16-in long. A Masonite door divided the stem into starting box and alley. The entire maze was painted gray and was placed in a gray surround where uniform lighting was provided throughout the maze. Gray food cups were placed in the goal end of each arm. A set of stimulus inserts was used which covered the three walls and floor of the maze arms. A different black-white pattern was painted on each insert. The patterns were (1) homogeneous black or white, (2) a simple pattern (S) in which half the insert was homogeneous black and half homogeneous white, (3) a wide vertical pattern (WV) which had four, 4-in vertical stripes of alternating black and white, (4) a horizontally striped pattern $(\mathrm{H})$ of $1 / 2$-in black and white stripes, (5) a narrow vertical pattern (NV) of $1 / 2$-in vertical stripes and (6) a checkerboard pattern (C) of $1 / 2$ in black and white squares. Patterns 2-6 had equal amounts of black and white to minimize possible effects due to brightness preferences.

\section{Procedure}

The general procedure consisted of three days pretest exposure to the maze with the same pattern in each arm. For a given rat the same pattern was presented each day. On days one and two, S was individually given $5 \mathrm{~min}$. of free maze exploration each day. On day three, each $\mathrm{S}$ was given seven unrewarded free-choice trials. The side entered most often was called the "preferred" side and the pattern in the other, "nonpreferred," side was changed in testing. On the following test days, a test trial consisted of 15 sec. in the start

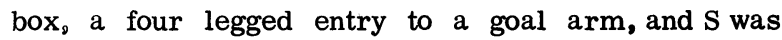
detained in the selected arm for $-15 \mathrm{sec}$. or until the food was eaten. Food reward consisted of four $45 \mathrm{mg}$ pellets (P. J. Noyes). One half hour after the daily trial Ss were given one hour ad. lib. feeding. Ss were about 22-1/2 hr. deprived when run.

Experiment I:

Seven male and eight female Ss were given one trial per day for 15 days. Half of each sex group had the homogeneous black insert present on pretest trials and the remaining Ss had homogeneous white. In testing, the $\mathrm{H}$ pattern was substituted on the non-preferred pretest side. Eight Ss were presented food in the complex arm (Group $\mathrm{C}+$ ) and seven had food in the homogeneous arm (Group C-).

\section{Experiment II:}

During the pretest exposure both arms contained the $\mathrm{S}$ pattern for all Ss. Twenty four Ss were assigned to three groups. Control group SS had the Spattern in both arms on all test trials and food was presented in the non-preferred side. Two experimental groups were presented a different pattern in one arm in each of four testing stages, while the $S$ pattern remained in the alternate arm during all four stages. The changing arm was the non-preferred arm. The patterns were always presented in order of increasing complexity (WV, H, NV, C). One experimental group was given food in the arm containing the sequentially changing patterns (Group $\mathrm{C}_{+}$) and the other group was presented food in the arm containing the $\mathrm{S}$ pattern (Group $\mathrm{C}-$ ). 
TABLE I

Mean number correct (food rewarded) responses

\begin{tabular}{ccccc} 
Experiment & Trials & Group C & Group SS & Group C- \\
\hline I & $1-15$ & 12.625 & & 7.714 \\
\hline II & 11 & 4.250 & 2.750 & 1.750 \\
\hline III & $1-16$ & 13.000 & 12.500 & 7.625 \\
\hline
\end{tabular}

Each group was balanced with respect to sex and experimenter. ${ }^{2}$ Sixteen daily test trials were given. Pattern WV was presented for three trials, pattern $\mathrm{H}$ for seven trials, pattern $\mathrm{NV}$ for three trials, and pattern $\mathrm{C}$ for three trials.

Experiment III:

Four female and seven male Ss were randomly assigned to two groups. All Ss on all trials had a choice between the $\mathrm{S}$ pattern and the $\mathrm{NV}$ pattern. Six Ss were presented food in the arm with the $S$ pattern (Group C-) and five had food in the arm with the NV pattern (Group $\mathrm{C}+$ ). The major difference between this experiment and the first two was that the position of the food rewarded arm varied from trial to trial according to a Gellerman series (each rat had a different series). The seven pretest trials were omitted and Ss $\therefore$ ad only two days pretest exposure.

\section{Hesults and Diseussion}

On the basis of previous response to change studies (e.,., Kivy, Earl \& Walker, 1956; Dember, 1956) it was expected that more Ss would enter the changed arm on trial one then would enter the unchanged arm. On the first test trial, 13 out of .15 entered the changed arm in Experiment I, 12 out of 16 in Experiment II, and 10 out of 11 in Experiment III. These results are all significant by a one-tailed binomial test $(p<.004$, $\mathrm{p}<.038, \mathrm{p}<.006$, for Experiments I, II and III respectively). These trial one results add generality to previous similar findings since $24 \mathrm{hr}$. intervened between exposure and test trials and in Experiments II and III the change was one of pattern as opposed to brightness.

Analysis of variance and t-tests were based on the number correct, i.e., food rewarded, responses. In Experiment I Group C+ made more correct responses than group $C-(t=13.529, d f=13, p<.001)$. Similarly, in Experiment III, Group $\mathrm{C}+$ made more correct responses $(t=1.834, d f=9, p<.05)$.

In Experiment II, analysis of variance of correct responses for the first six trials indicated a significant difference between the groups $(F=5.72, \mathrm{df}=2 / 21$, $\mathrm{p}<.025$ ). Duncan's test (Edwards, 1960) indicated that Group $\mathrm{C}+$ made more correct responses than group
C- $(p<.005)$ and more than Group SS $(p=.06)$. Group SS made more than Group $C-(p<.10)$. Analysis of variance of scores based on all 16 trials also indicated significant differences between the groups $(F=8.52$, $\mathrm{df}=2 / 21, \mathrm{p}<.005)$. However, Duncan's test indicated that Groups C+ and SS did not differ from each other although they both differed from Group $C-(p<.005)$.

These results indicate that: (1) food reward is not a uniformly sufficient condition for reinforcing behavior in hungry rats, (2) it is not necessary for Ss to be reared in sensory deprivation for stimulus complexity to be effective in the food reward situation employed, and (3) comparing these results with those reported by Sackett et al (1963), intertrial interval appears to be important where visual stimulus complexity and food are both employed as rewards.

In general, these results conform to a prediction suggested by Harlow (1959) that if the rewarded stimulus is the "preferred" stimulus, "learning" may occur in very few trials. A problem, however, is to make a reasonably rigorous a priori prediction as to which alternative will be selected on the early trials. Several solutions to this problem have proved effective. For example, Sackett et al (1963) reared their Ss under conditions relevant to the test situation and in the present study Ss were given pretest maze exposure. Similar pretest exposure to establish a reference point from which to predict trial one responses has been effective with children as Ss (May, 1963).

\section{Referenees}

Berlyne, D. E. Conflict, arousal and curiosity. New York: McGraw Hill, 1960.

Dember, W. N. Response by the rat to environmental change. $J$. comp. physiol. Psychol. 1956, 49, 93-95.

Dember, W. N., \& Earl, R. W. Analysis of exploratory, manipulatory and curiosity behavior. Psychol. Rev. 1957, 64, 91-96.

Edwards, A. L. Experimental design in psychological research. New York: Rinehart and Company, Inc., 1960.

Harlow, H. F. Learning set and error factor theory. In S. Koch (Ed.), Psychology: A study of a science, Vol. 2. New York: McGraw Hill, 1959.

Kivy, A. L., Earl, R. W., \& Walker, E. L. Stimulus context and satiation. J. comp. physiol. Psychol. 1956, 49, 9-92.

May, R. B. Stimulus selection in preschool children under conditions of free choice. Percept. mot. Skills, 1963, 16, 203-206.

Myers, A. K., \& Miller, N. E. Failure to find a learned drive based on hunger; evidence for learning motivated by "exploration." J. comp. physiol. Psychol. 1954, 47, 428-436.

Sackett, G. P.,Lee, Patricia, \& Treat, R. Food versus perceptual complexity as rewards for rats previously subjected to sensory deprivation. Science, 1963, 141, 518-520.

\section{Notes}

1. This research was supported in part by N.I.H. fellowship MPM15,908 to R. B. May, and MH 24,639 to S. Pollock.

2. Subjects in Experiment I were run by S. Pollock, in Experiment II by R. B. May and K. L. Beauchamp and in Experiment III by R. B. May. 